\title{
Line Voltage Detector for SMES System Designed to Protect From Momentary Voltage Drop
}

\author{
Hirotaka Chikaraishi, Kazuo Hayashi, Toshiyuki Mito, Kagao Okumura, and Ryo Abe
}

\begin{abstract}
For the precision industrial plants, a stable electrical power source is the one of the key components as known as well. Usually, a battery type UPS is used to protect computers from the power failure, but it cannot protect the whole plant because its capacity is too small to supply for all facilities. A short time SMES system is suitable to cover this problem. It will supply the enough power to the plant while the line voltage is momentary dropped. The target plant may be sensitive for the line voltage drop, a highspeed detection of voltage drop is required and a detector that uses two detect method in parallel, was developed. This paper introduces the voltage detector developed for the SMES system.
\end{abstract}

Index Terms-DC power supplies, SMES UPS, voltage drop detector.

\section{INTRODUCTION}

$\mathbf{M}$ ANY precision industrial facilities such as facility for an electronic device, LCD panel or imaging device are on the stage in the world. In these facilities, the stability of electrical power is one of the important keys to operate continuously and some UPS's are used to protect computer systems in them. For this purpose, a battery type UPS is widely considered but its capacity is not so large and is usually less than $100 \mathrm{~kW}$. Therefore, the battery type UPS is used for only computer systems in the facility. If the voltage drop occurred in an utility power line, the plants in the facility may be interrupted because the other components are not done backup. To protect the whole facility, a SMES, which has a larger capacity, is designed.

In the following sections, we describe the outline of our UPS system, first. Next, a voltage detector for the UPS is introduced.

\section{OUTLINE OF A SMES SYSTEM}

Fig. 1 shows a diagram of the SMES UPS and Table I shows specifications of the SMES module. In this SMES, a dry superconducting coil, which does not use cryogenic helium as coolant, is used [1], [2]. When more large capacity is required, the parallel connection of UPS modules can be applied.

A type shown in Fig. 2(a), the converter compensates voltage sag and the constant voltage drives the load [4], [5]. With this type, if the utility power line is cut out by a circuit breaker, the voltage compensator cannot supply any power to the load. Additional to it, if the voltage drop is unbalanced shown as following section, the phase of line voltages are changed and the

Manuscript received October 21, 2003. This research project is supported by NEDO Japan.

H. Chikaraishi and T. Mito are with the National Institute for Fusion Science, Oroshi 322-6, Toki, Gifu, Japan (e-mail: hchikara@nifs.ac.jp).

K. Hayashi and R. Abe are with IDX Co., Ltd.

K. Okumura is with Technova Co., Ltd.

Digital Object Identifier 10.1109/TASC.2004.830100

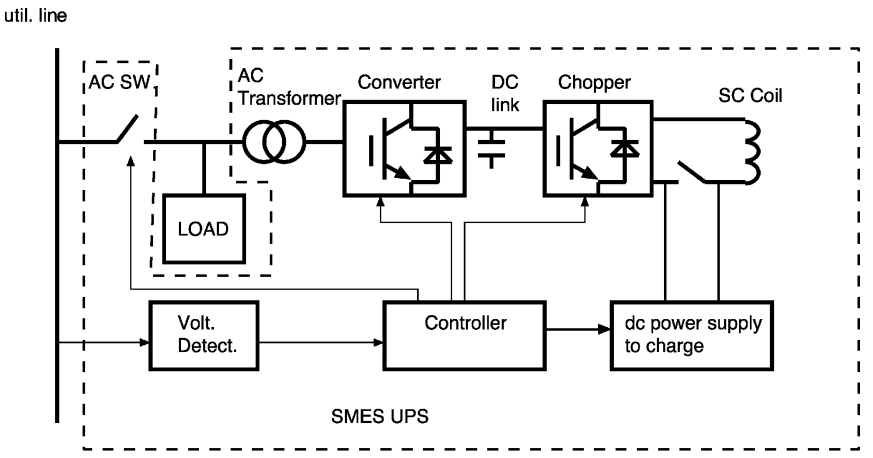

Fig. 1. Diagram of a SMES UPS.

TABLE I

SPECIFICATIONS OF SMES UPS

Specification of the system

Line volt.: $6.6 \mathrm{kV}$, curr. $100 \mathrm{~A}$

Rated power: $1 \mathrm{MW}$ (Larger power can be compensated with parallel operation)

Compensation time: 1 second, Operation delay: less than 1/2 cycle Necessary floor space: $12 \mathrm{~m}^{2}$

Specification of the coil

Curr.: $1 \mathrm{kA}$, Volt.: $1.4 \mathrm{kV}$, Inductance $4 \mathrm{H}$, Stored energy: $2 \mathrm{MJ}$

Specifications of components

AC Switch

Line volt.: $6.6 \mathrm{kV}$, curr. $100 \mathrm{~A}$, Operation delay: less than $10 \mathrm{~ms}$ Transformer

Prim. volt.: $6.6 \mathrm{kV}$, Second. volt.: $800 \mathrm{~V}$, Capacity: $1.2 \mathrm{MVA}$

Inverter and converter

$\mathrm{AC}$ side volt. and curr.: $800 \mathrm{~V}$ and $820 \mathrm{~A}$, DC link volt. and curr.: $1 \mathrm{kV}$ and $1 \mathrm{kA}$ Capacity: 1 MVA 10 seconds, Cooling: air cooled

converter must generate the higher voltage to compensate this voltage phase shift.

The diagram shown in Fig. 2(b) is a rectifier inverter type, which is used in some battery type UPS [6]. In this structure, a full rated power capacity rectifier and inverter are necessary. Therefore, a large scale UPS is difficult to construction with this type because.

Fig. 2(c) shows a UPS with AC switch. Although a fast AC switch is necessary in this structure, there are following merits; the converter works when a line fail and it is required short time ratings and a cool system becomes simple, it can compensate for any type of line fault. With these the merit, we selected this type.

\section{High-Speed Voltage DeteCtor}

In our UPS, the high-speed voltage drop detector is one of key components. Table II shows the specification of it and the detect delay time shown in the table is one of the most important term. Fig. 3 shows a block diagram of the detector and it uses 


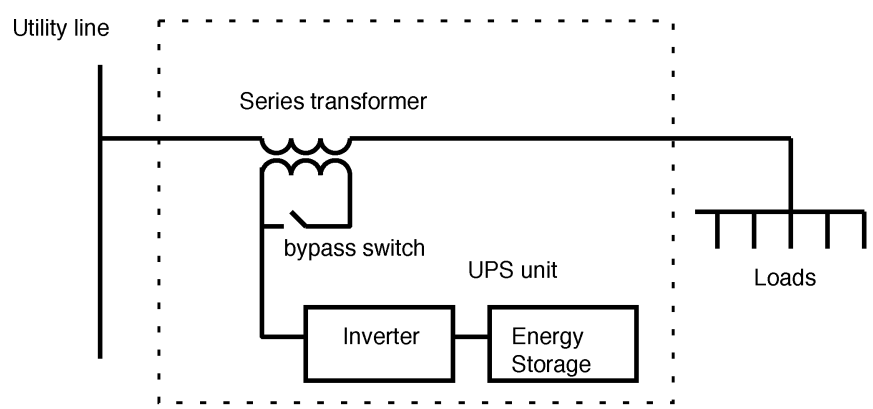

(a)

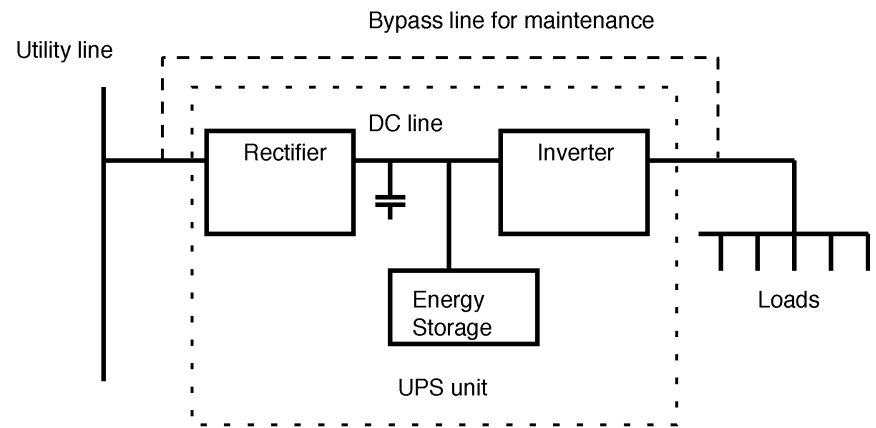

(b)

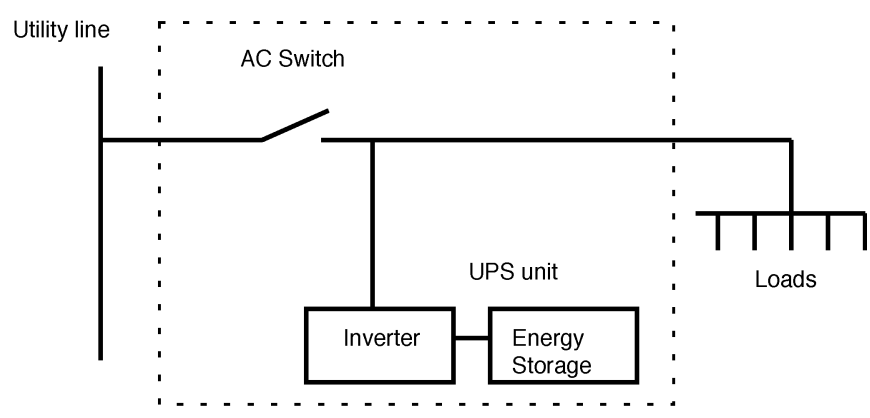

(c)

Fig. 2. Typical type of power compensator. (a) Series voltage compensator; (b) Rectifier-inverter type UPS; (c) UPS using an ac switch.

two type of detection in parallel. One, which part is surrounded by dashed line, is based on a real time wave comparator and the other, which is surrounded by dot-dashed line, is based on the instantaneous rms value comparator. With mixing of the outputs of these two units, the high-speed and high accuracy detection is realized.

\section{A. Line Voltage Waveform Compare}

In the real time waveform compare unit, a PLL circuit tracks the phase angle of the line voltage and reference sinusoidal line voltage references are generated. The gain $\mathrm{K} 1$ in this diagram determines a detection lever and the gain $\mathrm{K} 2$ determines return level.

When a phase angle of reference signal is around zero or $\pi$, the reference and actual line voltages are small, and some noise or wave distortion may makes error detection. To avoid this miss operation, a switch after the comparator blocks the signal when $\theta<\pi / 6,5 / 6 \pi<\theta<7 / 6 \pi$ or $11 / 6 \pi<\theta$, where $\theta$ is the phase angle of reference. With using three phase line voltage, we get three signals, which have phase separation of $\pi / 3$.
TABLE II

SPECIFICATIONS OF VOLTAGE DROP DETECTOR

\begin{aligned} & \hline \hline Input voltage: $200 \mathrm{~V}$ in three phase \\ & Detect level of voltage drop *: $-15 \%$ of nominal value \\ & Detect level of voltage recover *: $-10 \%$ of nominal value \\ & Delay of voltage drop detection: $100 \mu \mathrm{s} \\ &$ Delay of voltage recovers detection: $1 \mathrm{cycle} \\ &$\hline \hline\end{aligned}

* Detect levels are selectable

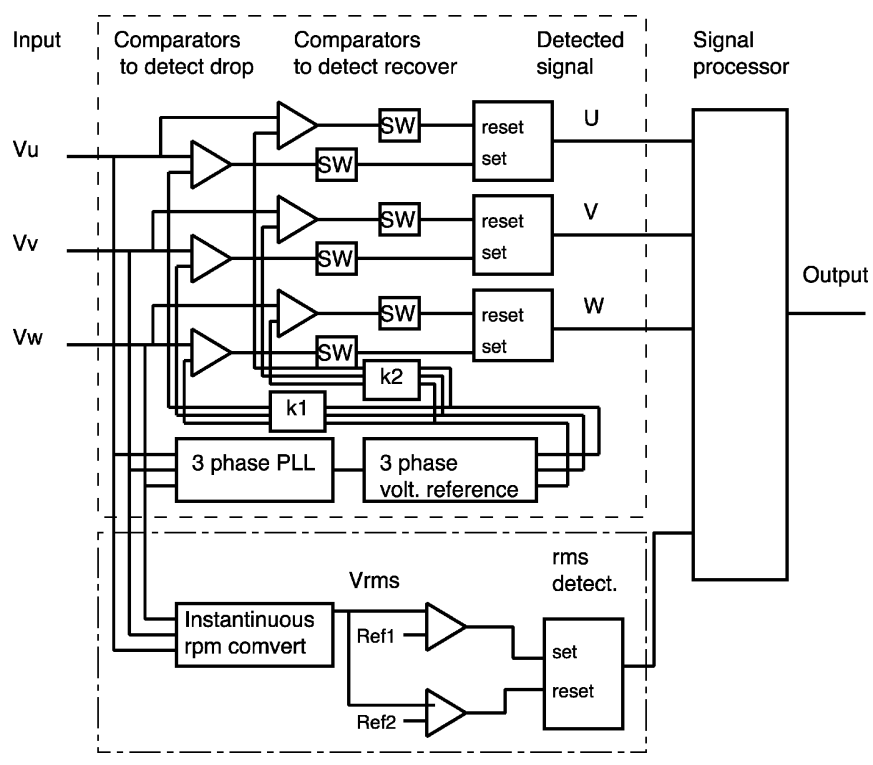

Fig. 3. Diagram of a voltage drop detector.

These three signals are mixed and a final output signal, which has no delay time, is generated. The operation of this circuit is shown in Fig. 4.

\section{B. Instantaneous rms Voltage Detection}

In another unit, an instantaneous rms value is used to detect the voltage drop. $V_{r m s}$ is calculated with following equation;

$$
V_{r m s}=\sqrt{V_{u}^{2}+V_{v}^{2}+V_{w}^{2}}
$$

Because the instantaneous rms value becomes a DC signal for balanced three-phase voltage, the comparator outputs a continuous DC signal as shown in Fig. 4.

\section{Signal Processor}

In some cases such as a one line-grounding fault, the line voltages become unbalanced and each comparator generates pulsated output signal. A signal processor, which includes logical OR of all detector output and an off delay timer, removes hunching and it makes a continuous signal.

\section{EXPERIMENTAl RESUlts of Voltage DROP DETECTION}

A prototype model of the voltage drop detector is connected to a utility line of the NIFS and is testing. In this experiment, the confirmation of the detection time delay and the stability of the circuit are objects. Therefore, voltage recovery detectors and signal processor are not built in the prototype circuit. To observe 


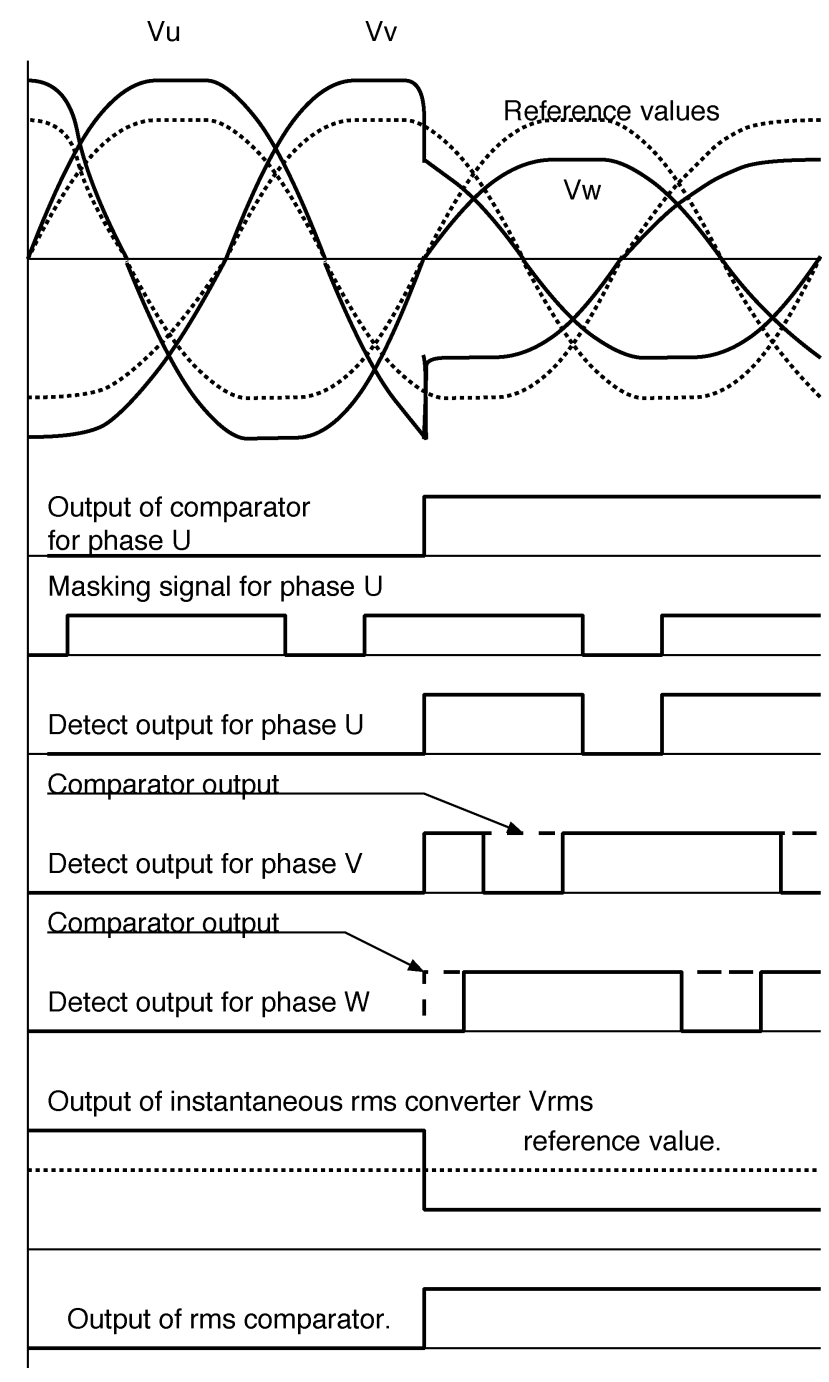

Fig. 4. Operation a voltage drop detector.

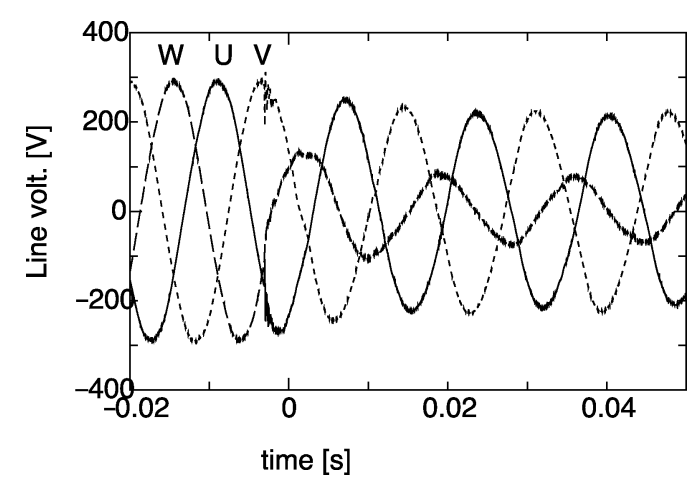

Fig. 5. Line voltage waveforms in the test operation using an actual utility line.

the operation of testing circuit, the input line voltages and each output of comparators are recorded.

Figs. 5 and 6 show the line voltage waveforms and comparator output signals when the line voltage dropped. As shown in the figure, a line voltage of phase $\mathrm{W}$ dropped to $501 \%$ of normal level. Line voltages of phase $\mathrm{U}$ and $\mathrm{V}$ dropped only $201 \%$ and their phases are shifted from normal position. With this phase shift, the comparators for phase $\mathrm{U}$ and $\mathrm{V}$ output voltage

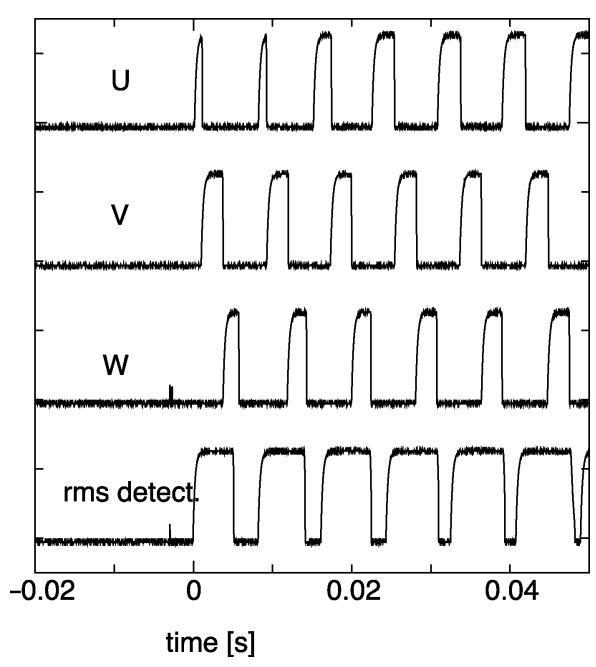

Fig. 6. Comparator output signals in the test operation.

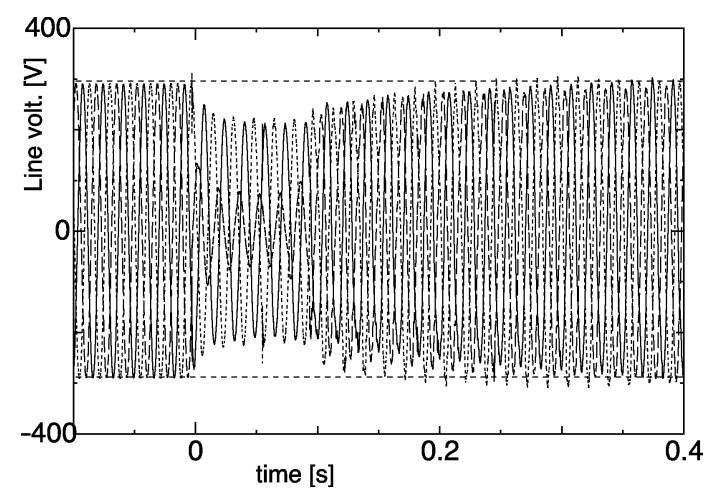

Fig. 7. Whole waveforms of line voltage in the test operation using actual utility line.

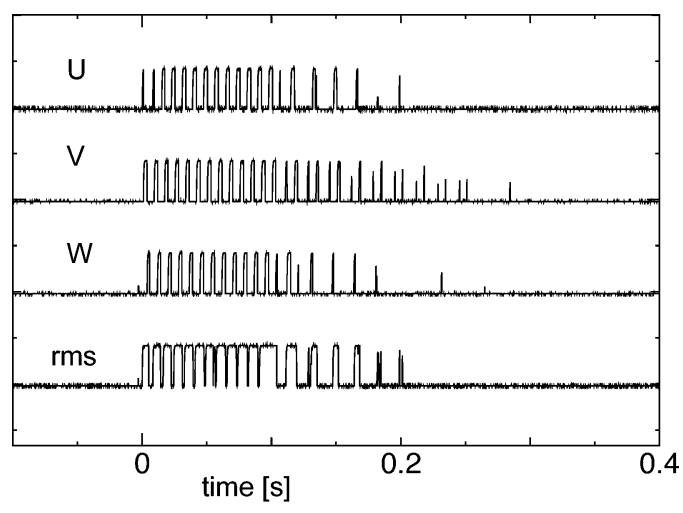

Fig. 8. Whole waveforms of comparator output in the test operation using actual utility line.

drop signals. In this figure, each comparator output signal is pulsated but no delay of detection was observed.

Figs. 7 and 8 shows whole waveforms of the test result. The voltage sag is almost recovered in 5 cycles but line voltages are not recovered to the normal level. The line voltages are built up slowly and they reach to the normal level at time $=0.3 \mathrm{~s}$. In this time region of $0.1 \mathrm{~s}<$ time $<0.3 \mathrm{~s}$, the voltage drop detectors make some short pulses and they re-trigger flip-flops shown in 
Fig. 4. These flip-flops will be reset by voltage recovery detectors and an off delay timer in the signal processor will remove the hunching and reforms the detector output.

This detector circuit has been connected to an actual line and tested almost one year and no miss detection is observed.

\section{SUMmary}

This paper describes the line voltage detector for a short time SMES UPS system. The line voltage detector includes two different type of detection for high-speed and high accuracy detection is designed and tested in actual utility network. The test results using actual electrical utility network show the detector satisfies the required detection speed and stability. Now, other components for this SMES proto system such as an inverter, DC-DC converter, and superconducting coils are constructing.

\section{ACKNOWLEDGMENT}

In the construction and test of proto type circuit, the staff of Technova, IDX, and NIFS helped with the project. The authors would like to thank the staff.

\section{REFERENCES}

[1] T. Mito, K. Okumura, H. Chikaraishi, T. Baba, K. Yamauchi, M. Yokota, A. Kawagoe, F. Sumiyoshi, M. Iwakuma, T. Henmi, K. Hayashi, and R. Abe, "Development of UPS-SMES as a Protection From Momentary Voltage Drop,", this conference.

[2] A. Kawagoe, F. Sumiyoshi, T. Mito, H. Chikaraishi, T. Baba, K. Okumura, M. Iwakuma, T. Henmi, K. Hayashi, R. Abe, T. Ushiku, and I. Inoue, "Design and Fabrication of Conduction Cooled LTS Pulse Coil for $100 \mathrm{~kJ}$ Class UPS-SMES as a Protection From Momentary Voltage Drop,", this conference.

[3] H. Salbert, D. Krischel, A. Hobl, M. Schillo, N. Blacha, A. Tromm, and W. Roesgen, "2 MJ SMES for an uninterruptible power supply," IEEE Trans. Appl. Supercond., vol. 10, no. 1, pp. 777-779, March 2000.

[4] A. K. Kalafala, J. Bascunan, D. D. Bell, L. Blecher, F. S. Murray, M. B. Parizh, M. W. Sampson, and R. E. Wilcox, "Micro superconducting magnetic energy storage (SMES) system for protection of critical industrial and military loads," IEEE Trans. Magn., vol. 32, no. 4, pp. 2276-2279, July 1996.

[5] R. Schottler and R. G. Coney, "Commercial application experiences with SMES," Power Engineering Journal, vol. 13, no. 3, pp. 149-152, June 1999.

[6] S. A. O. da Silva, P. F. Donoso-Garcia, P. C. Cortizo, and P. F. Seixas, "A three-phase line-interactive UPS system implementation with series-parallel active power-line conditioning capabilities," IEEE Trans. Industry Applications, vol. 38, no. 6, pp. 1581-1590, Nov.-Dec. 2002. 